\title{
Spontaneous Pneumomediastinum: Origin Identified by Chest Computed Tomography
}

\author{
Toshimichi Kaneki, Keishi Kubo, Shusuke Sone* and Akira Kawashima**
}

\begin{abstract}
Spontaneous pneumomediastinum (SPM) is an uncommon disorder. The mechanism of spontaneous pneumomediastinum has been speculated as follows: when air pressure in the alveoli rapidly increases, free air leaks from ruptured alveoli and accumulates along the bronchovascular tissue sheath, and then free air moves toward the mediastinum. In this case report of a 19-year-old man of SPM, a chest computed tomography (CT) revealed air in a tubular shape along the pulmonary artery in the apico-posterior segment of the left lung field. This is the first case in which the process of SPM could be identified by chest $C T$.
\end{abstract}

(Internal Medicine 37: 877-879, 1998)

Key words: spontaneous pneumomediastinum (SPM), mechanism of SPM, rupture of alveoli, computed tomography

\section{Introduction}

Pneumomediastinum or mediastinal emphysema is the presence of air in the mediastinum (1). This disorder occurs spontaneously, due to either some underlying disease (medical mediastinal emphysema) or due to trauma, surgery, or due to diagnostic or therapeutic procedures (1). Spontaneous pneumomediastinum (SPM) or spontaneous mediastinal emphysema, first reported by Hamman in 1939 (2), is a relatively uncommon disorder. SPM occurs without an apparent precipitating factor or disease, usually in young people, and resolves within approximately 7 days (3-8). A possible pathogenetic sequence of SPM was delineated by Macklin and Yoshimura et al $(9,10)$ who speculated that the rapid increase in intra-alveolar pressure in the alveoli is the first step, and after that free air leaks from the ruptured alveoli and then accumulates along the bronchovascular tissue sheath. The free air then moves into the mediastinum. No report of computed tomography (CT) imaging demonstration of this process has been found in the literature to date.

For editorial comment, see p 802.

In the present case report of a 19-year-old man of SPM, the chest CT clearly revealed a radiolucent line along the pulmonary artery in the apico-posterior segment of the left lung field.
The CT finding might correlate with the process of SPM as described by Macklin $(10,11)$. According to our literature search, there have been few case reports or review articles in which the origin of SPM could be identified.

\section{Case Report}

A 19-year-old healthy man, body weight $58 \mathrm{~kg}$ and body height $171 \mathrm{~cm}$, had spontaneously felt retrosternal and had cervical pain the previous evening. The day before he carried a boy weighing $8.8 \mathrm{~kg}$ while playing. The pain did not improve, and 12 hours later he was admitted to the Okaya City Hospital. On admission, marked subcutaneous emphysema was palpable over the precordia and extending to the neck. He disclosed a respiratory rate of $22 / \mathrm{min}$, heart rate of $76 / \mathrm{min}$ and systemic blood pressure of $136 / 68 \mathrm{mmHg}$. Snow grip sounds associated with the heart beat (Hamman's sign) were audible on the left anterior chest. No rales were noted on the lungs. Laboratory data included the following values: hemoglobin $(\mathrm{Hb}) 15.6 \mathrm{~g} / \mathrm{dl}$; hematocrit (Ht) $45.1 \%$; red blood cell (RBC) $523 \times 10^{4} / \mathrm{mm}^{3}$; white blood cell (WBC) $6,900 / \mathrm{mm}^{3}$; platelet count $30.5 \times 10^{4}$ / $\mathrm{mm}^{3}$; C-reactive protein (CRP) $1.72 \mathrm{mg} / \mathrm{dl}$; aspartate aminotransferase (AST) 32 IU; alanine aminotransferase (ALT) 37 IU; lactate dehydrogenase (LDH) 22 IU; creatine phosphokinase (CPK) 150 IU. Arterial blood gas analysis under room air revealed: partial pressure of oxygen $\left(\mathrm{PaO}_{2}\right) 84.3$ Torr; partial

From the First Department of Internal Medicine and *the Department of Radiology, Shinshu University School of Medicine, Matsumoto and **Division of Internal Medicine, Okaya City Hospital, Okaya

Received for publication April 2, 1998; Accepted for publication July 27, 1998

Reprint requests should be addressed to Dr. Keishi Kubo, the First Department of Internal Medicine, Shinshu University School of Medicine, 3-1-1 Asahi, Matsumoto 390-8621 


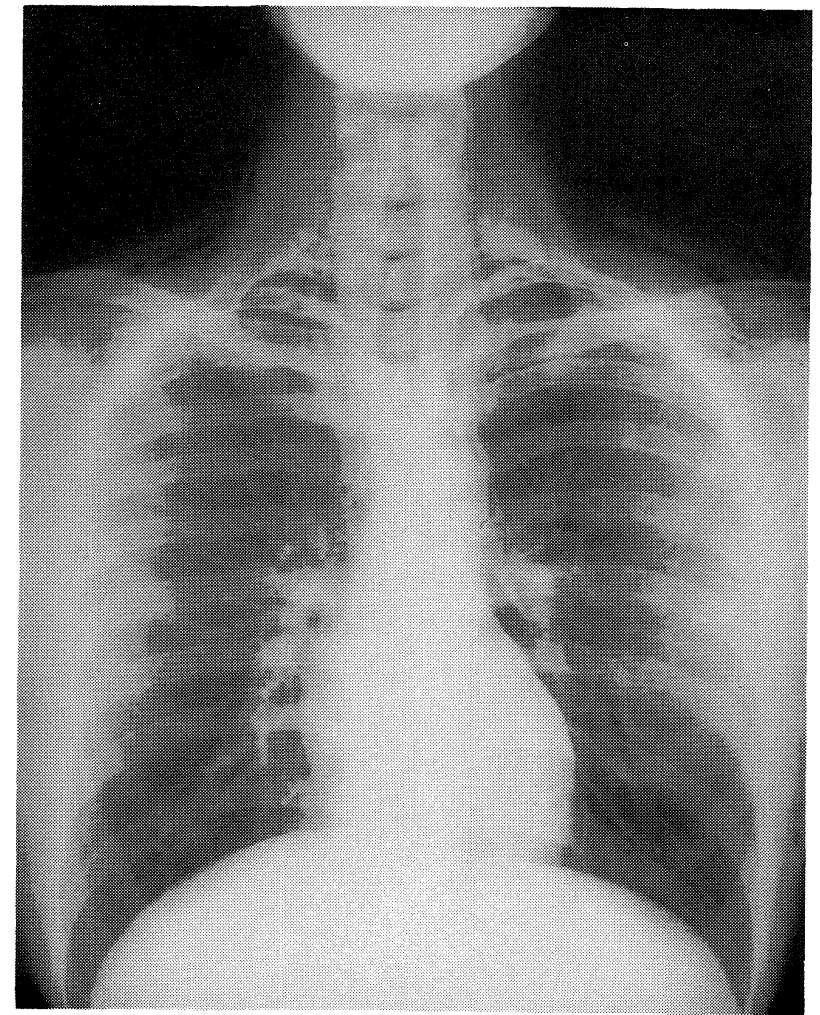

Figure 1. A chest $\mathrm{X}$-ray on admission shows a marked streaky strand-like radiolucent space on the neck, upper mediastinum and around the heart.

pressure of carbon dioxide $\left(\mathrm{PaCO}_{2}\right) 35.0$ Torr; $\mathrm{pH}$ 7.433. A chest X-ray (CXR) showed translucent lines along the major vessels with marked streaky strands on the neck, upper mediastinum and around the heart (Fig. 1). The chest CT scans (Fig. $2 \mathrm{~A})$ revealed marked air accumulation around the aorta, trachea, and the vessels of the mediastinum together with deep cervical emphysema and subcutaneous emphysema. No bulla or bleb was detected. As a characteristic CT finding, a tubular shape air along the pulmonary artery was identified in the apicoposterior segment $(\mathrm{S} 1+2)$ of the left lung (Fig. 2A, arrow).

$\mathrm{He}$ was diagnosed as having SPM. Five days later his complaints, subcutaneous emphysema, Hamman's sign and the abnormal shadows on CXR disappeared without any special treatment. The air space observed along the bronchovascular bundle on the chest $\mathrm{CT}$ taken on admission, had disappeared by the 8th hospital day (Fig. 2B).

\section{Discussion}

The present case was a typical SPM, as noted in case reports $(3,4)$ and review articles of SPM (5-9). He was young and complained of chest and neck pain with subcutaneous emphysema. The Hamman's sign was detected by physical examination on admission. He showed a benign self-limited course.

The development of SPM is explained as follows. The rapid increase of the air pressure in the alveoli is considered to be the

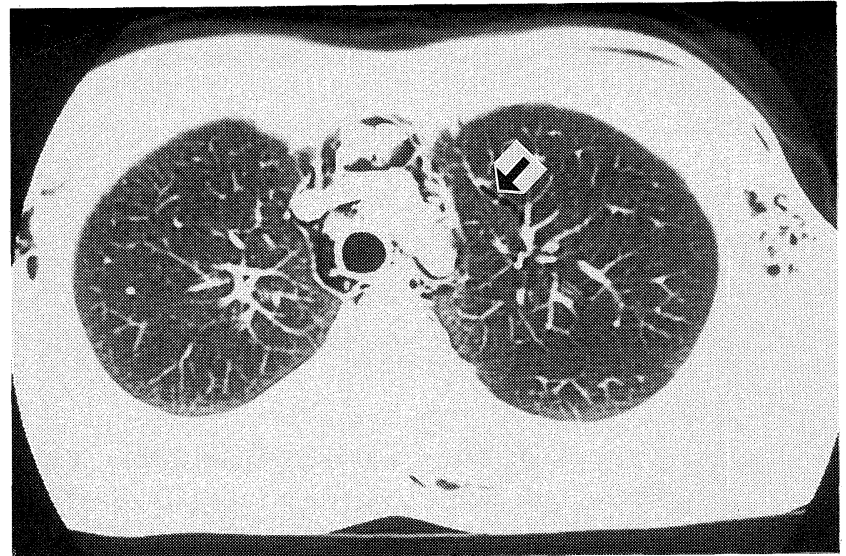

A

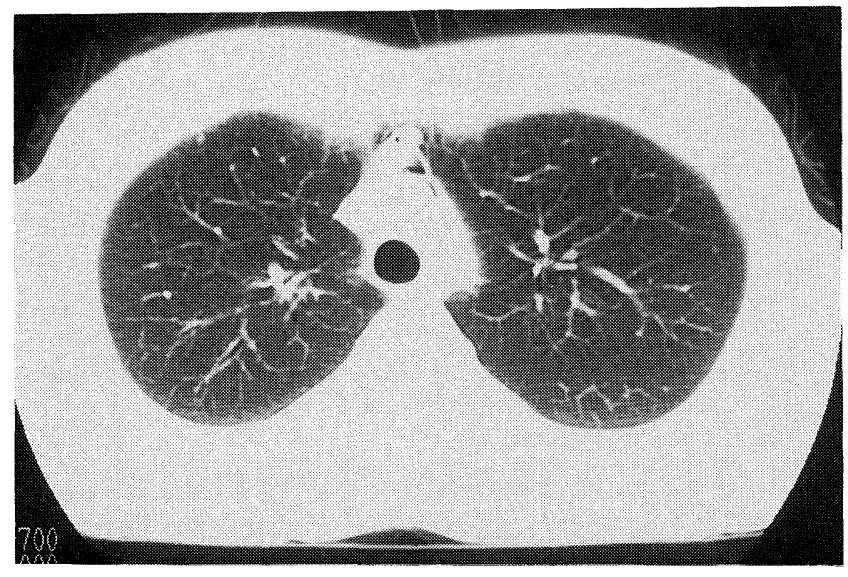

B

Figure 2. A chest $\mathrm{CT}$ on admission (2A) and on 8th hospital day (2B). Marked air accumulation is noted around the aorta, trachea, and the vessels of the mediastinum and subcutaneous emphysema. Moreover a radiolucent air space is found along the pulmonary artery in the S1+2 of the left lung field (Fig. 2A, arrow); this finding disappears by the 8th hospital day (Fig. 2B).

first step in the development of SPM, and in most reported cases SPM has developed during sports, physical activity, or violent coughing. In the present case, the patient lifted up a boy 12 hours before he felt the chest pain. It is probable that at that time, the air pressure in the alveoli rapidly increased and SPM occurred.

Macklin et al $(10,11)$ have proposed the following hypothesis of the mechanism of SPM, based on animal models: when air pressure in the alveoli rapidly increases, free air leaks from ruptured alveoli. The free air then invades the interstitial tissue of the lung and accumulates along the bronchovascular tissue sheath. The free air moves toward the mediastinum and accumulates in it. Sone et al (12) demonstrated the existence of pathways between the mediastinal structures allowing the spread of free air from one region to another using CT scans obtained after pneumomediastinography. They did not find any air tracking from the mediastinum up stream into the lung. 


\section{Spontaneous Pneumomediastinum}

Macklin's hypothesis has never been clinically demonstrated. In the present case, the chest CT on admission revealed a radiolucent air space along the pulmonary artery in the $\mathrm{S} 1+2$ of the left lung (Fig. 2A, arrow), and this finding disappeared after 8 days (Fig. 2B), when he recovered. Therefore, we believe that this chest CT evidence is supportive of the hypothesis of Macklin et al $(10,11)$.

The prognosis in SPM is good, and recurrence is an exceptional event (4). The present patient has had no recurrence to date.

\section{References}

1) Bodey GP. Medical mediastinal emphysema. Ann Intern Med 54: 46-56, 1960.

2) Hamman L. Spontaneous mediastinal emphysema. Bull Johns Hopkins Hosp 64: 1-21, 1939.

3) Munsell WP. Pneumomediastinum. A report of 28 cases and review of the literature. JAMA 202: 689-693, 1967.

4) Abolnik I, Lossos IS, Breuer R. Spontaneous pneumomediastinum. A report of 25 cases. Chest 100: 93-95, 1991.

5) Hamman L. Mediastinal Emphysema. JAMA 128: 106, 1945.

6) Crylak D, Milne ENC, Imray TJ. Pneumomediastinum: a diagnostic problem. Crit Rev Diag Imaging 23: 75-117, 1984.

7) Maunder RJ, Pierson DJ, Hudson LD. Subcutaneous and mediastinal emphysema. Pathophysiology, diagnosis, and management. Arch Intern Med 144: 1447-1453, 1984.

8) Bejvan SM, Godwin JD. Pneumomediastinum: Old signs and new signs. AJR Am J Roentgenol 166: 1041-1048, 1996.

9) Yoshimura T, Takeo G, Souda M, Ohe H, Ohe N. CT demonstration of spinal epidural emphysema after strenuous exercise. J Comput Assist Tomogr 14: 303-304, 1990.

10) Macklin CC. Transport of air along sheaths of pulmonic bloodvessels from alveoli to mediastinum. Arch Intern Med 64: 913-926, 1939.

11) Macklin MT, Macklin CC. Malignant interstitial emphysema of the lungs and mediastinum as an important occult complication in many respiratory diseases and other conditions: an interpretation of the clinical literature in the light of laboratory experiment. Medicine (Baltimore) 23: 281-358, 1944.

12) Sone $S$, Higashihara $T$, Morimoto $S$, et al. Potential spaces of the mediastinum: CT pneumomediastinography. AJR Am J Roentgenol 138: 1051-1057, 1982. 